\title{
Mixed Response in cGVHD
}

National Cancer Institute

\section{Source}

National Cancer Institute. Mixed Response in CGVHD. NCI Thesaurus. Code C103146.

Improvement in some organs, but worsening in others in chronic Graft versus Host

Disease (cGVHD); this is categorized as progressive disease. 